www.jmscr.igmpublication.org

Impact Factor 3.79

Index Copernicus Value: 5.88

ISSN (e)-2347-176x ISSN (p) 2455-0450

crossref DOI:_http://dx.doi.org/10.18535/jmscr/v4i02.77

Journal Of Medical Science And Clinical Research

IGM Publication

An Official Publication of IGM Publication

\title{
Dermatophilosis, Ectoparasite Infestation and Ring-Worm, Contemporary Cattle Herd's Ailments in South Eastern Nigeria
}

\begin{abstract}
Authors
Eugenie Youngo Tchokote ${ }^{1}$, R. A. Ukaha ${ }^{2}$, U. M. Oluchi ${ }^{3}$

${ }^{1}$ Dept. of Veterinary Medicine, College of Veterinary Medicine, Michael Okpara university of Agriculture,

Umudike, Abia state, Nigeria

${ }^{2}$ Dept. of Veterinary Surgery and Theriogeniology, College of Veterinary Medicine, Michael Okpara

University of Agriculture, Umudike, Abia state, Nigeria

${ }^{3}$ Veterinary Teaching Hospital, College of Veterinary Medicine, Michael Okpara university of Agriculture,

Umudike, Abia state, Nigeria

Corresponding Author

Tchokote Eugenie Youngo

Dept. of Veterinary Medicine, College of Veterinary Medicine, Michael Okpara University of Agriculture,

Umudike, Abia state, Nigeria

ABSTRACT

Dermatophilosis caused by dermatophilus congolensis, tick and lice and mites infestation, dermatomycosis affected $a$ herd of 120 cattle obtained from different sources. Animals were bovine specie of various breeds including White Fulani, Gudali, Bunaji and their crosses, Male and Female; Aged from 2-10 years and weighing 250-500kg. Ticks were boophilus and amblyomma spp mainly, lice (lignognathus spp), mites (sarcoptes spp). Animals were kept to be slaughtered for food, observed body conditions made them unwholesome for human consumption. The major clinical lesions observed on the severely affected animals were extensive scabs and crust on the head, neck, dorsum, flanks, inguinal region and limbs involving above $20 \%$ of the herd; circumscribed thick grey-white crusts raised conspicuously above the skin around a central area of alopecia; general tick and lice infestation. Digestion of scabs with KOH revealed presence of mites which continually damages the skin so encourage proliferation of infectious organism. This case study portrait the general complaints of most cattle owners and traders. Contrary to the opinion of many authors for who tick infestation produce immune suppression of the host rather than mechanical and biological effect, the successful treatment with combination therapy using oxytetracycline long acting $20 \mathrm{mg} / \mathrm{kg}$ deep IM and ivermectin $0.05 \mathrm{mg} / \mathrm{kg} S C$ suggest there is a incumbent mechanical factor complicating the condition. Its removal brought about effective and prompt healing. Dermatomycosis (ring worm) was found to be self limiting, lesions progressively disappeared when dermatophilosis and ectoparasitic infestation was cared for.

Key Words: Dermatophilosis, ring worm, tick and lice infestation, cattle.
\end{abstract}

\section{INTRODUCTION}

Dermatophilosis is a contagious zoonotic skin disease of domestic animals most commonly found in cattle in the tropics. The disease is non pruritic, and is characterized by exudative, proliferative or hyperkeratotic dermatitis in cattle, accompanied by 
the production of crusts and follicullitis. Dermatophilus congolensis the causative agent is a dimorphic organism which grows as branched filamentous mycelia containing dormant zoospores which are transformed by moisture to the infective stage of motile isolated cocci, invades the skin and causes skin disease ${ }^{[1]}$. Dermatophilosis had been reported to be more severe in ruminants and is of particular importance in tropical and subtropical regions ${ }^{[2]}$. Several factors are involved in the pathogenesis of dermatophilosis; among them are mechanical injury to the skin, rainfall, tick infestation, concurrent diseases and stress that compromise the host immune system. It is generally accepted that in the rainy season, owing to devitalizing effect on the skin barriers, the high relative humidity has a significant influence on the maturation and motility of the infective zoospores, and it has been claimed to be a major predisposing factor in the spread and epidemiology of the disease [1]. Frequently it is encountered during the raining season when the weather is humid and warm. It is a major constraint to cattle rearers and traders because of its highly contagious nature and difficulty in having the condition efficiently cured. Losses occur from direct animal loss, culling of affected animals, lameness and decreased work ability in affected oxen, reproductive failure from vulvalinfection/ infection of limbs in males in males preventing mounting, death from starvation of calves of dams with udder infection, loss of milk and milk production, downgrading of hide, loss of wool in sheep. Affected animals have low market value ${ }^{[3]}$. The disease can have epizootic proportions with consequent economic losses. Dermatophilosis does not generally impede the health of affected adult animals except when lesions are widespread involving about $50 \%$ of the body of the animal and/or there is intercurrent disease as pneumonia; it can cause heavy mortalities in very young animal especially in calves where plaque and crust formation may not occur and immune resistance not fully developed ${ }^{[4]}$.

Dermatomycosis as ringworm is mainly caused by microsporum and tricophyton spp in cattle. It could be self limiting except animal are kept in close confinement where infection and reinfection may occur. It is a major problem in young animals in which immune system is not fully developed, in immunocopromised adult animals and in animals in which long term treatment with some antibiotics and corticosteroids have been undertaken. Ringworm is more important as zoonotic disease for it is said that $80 \%$ of human ring worm from rural areas are contacted from cattle (Trichophyton verrucosum and Trichophyton mentagrophytes), horses (Tr.equinum (Microsporum equinum)), dogs cats and furred animals (Microsporum canis and $\mathrm{Tr}$. mentagrophytes (Microsporum gypseum)) ${ }^{[5,6]}$. In cattle the lesions are most commonly found on the neck, head and perineum and consist of heavy, greywhite crusts raised perceptibly above the skin, or simply alopecia ${ }^{[4]}$.

\section{MATERIALS AND METHOD: LOCATION AND CASE DEFINITION}

Attention of the Veterinary teaching hospital Michael Okpara University of Agriculture Umudike was called for the herd of cattle Umuahia Abia State kept for slaughter as food. Animals were considered unfit for consumption because of the skin diseases they had.

Skin scrapings were taken for culture and identification of causative agents, blood for haematology and haemoparasite, Ectoparasites for identification.

Parasitological and Mycological Examination: Direct microscopical examination was done for detection of mites in skin scrapings and/or fungal elements of dermatophytes on hair and wool. A small part of the sample (skin scrapings, hair or wool) was placed on a clean glass slide, a several drops of $\mathrm{KOH}$ solution of different concentrations (5-10-20\%) were added, covered with clean coverslip and gently pressed, the slide was gently heated (without boiling) for 10 - 15seconds. Prepared samples were examined microscopically under low and high power objectives for detection of fungal elements. 
Management Plan: Animals were treated with Oxytetracycline LA (Pantex ${ }^{(\mathrm{R})}$ Holland B.V.) IM $20 \mathrm{mg} / \mathrm{kg}$ three doses three days apart; Ivermectin (Kepromec ${ }^{(\mathrm{R})}$ Holland) SC $0.05 \mathrm{mg} / \mathrm{kg}$ two doses one week apart, Hydrocortisone (Pantex ${ }^{(\mathrm{R})}$ Holland) IM $2 \mathrm{mg} / \mathrm{kg}$ for $5 / 7$ in animals with very severe lesions and skin reaction. Owner was advised to isolate new arrivals for examination and possible quarantine before adding to the herd; use zinc oxide cream on animals with ringworm and observe drug withdrawal period (30 days after last treatment) before slaughtering.

\section{RESULTS AND ANALYSIS: CLINICAL FINDINGS}

On physical examination, animals had crust and scabs of various sizes and severity on different parts of the body and about $20 \%$ of the herd. Some had wet lesions pityriasis, showing some degree of irritations. Heavy tick and lice infestation, Circumscribed areas of alopecia on the body affecting mainly the dorsum of infected animals. Body Score: 3-4/5; Rectal temperature: 38-39\%; Respiratory rate: 17-20, Heart rate: 70-80bpm; Pulse: 80-90 bpm, Rumen motility: 2-3cycles/2min. Plates1,2, and 3 show skin lesions as observed clinically.
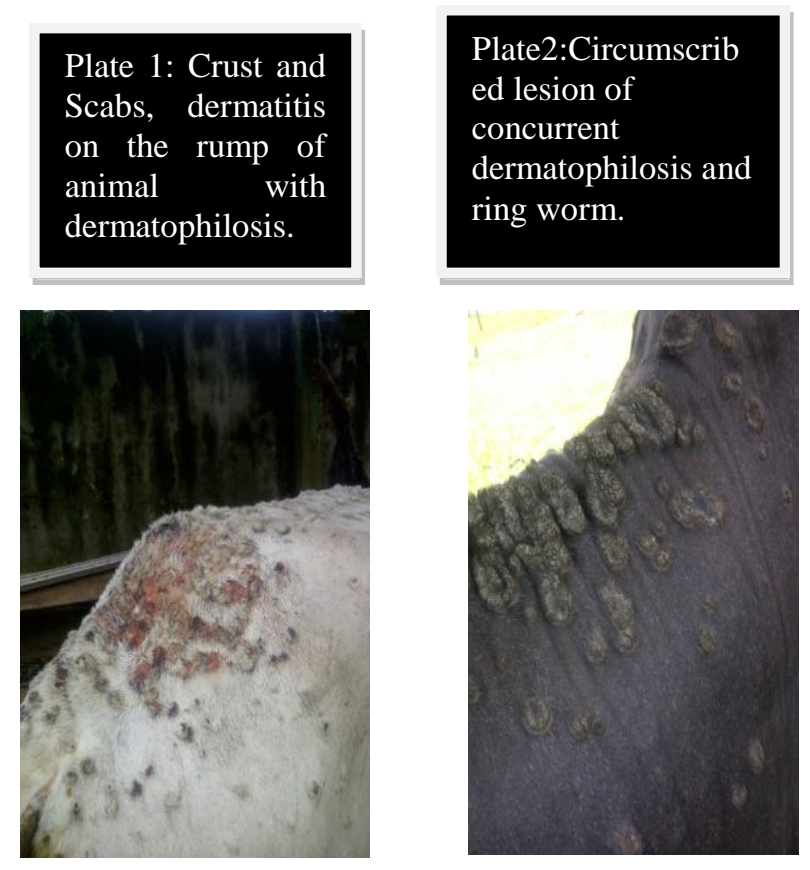

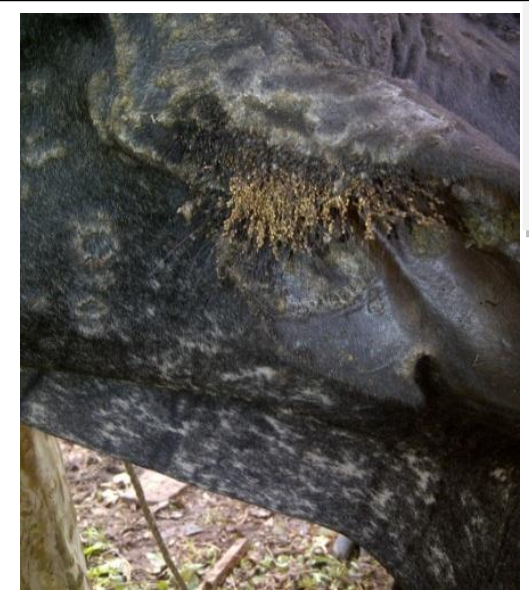

Fig 3: Heavy lice

infestation on the median

surface of the pinna of

affected cattle.

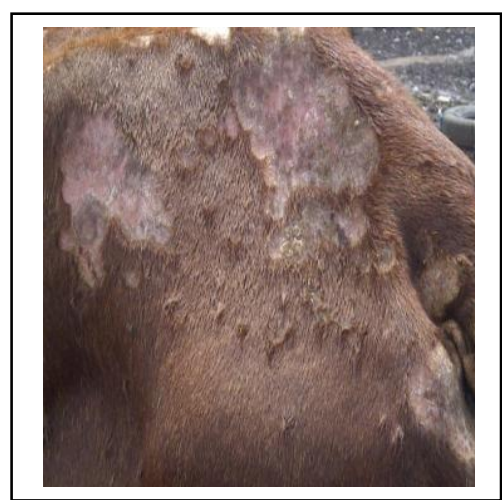

Plate 4:Dry patches of skin as crust and scabs fall off after treatment.

Laboratory results: Dermatophilus congolensis was identified cultures from skin scrapings in the dermatophilosis unit of the National Veterinary Research Institute Vom, ectoparasites were boophilus spp, embyomma varriegatum for the ticks, Lignognathus lice and sarcoptes mites. No fungal elements was identified on direct microscopic examination, complicating mites were found (plates E1 and E2) to perpetuate skin damage and encourage proliferation of dermatophilus.

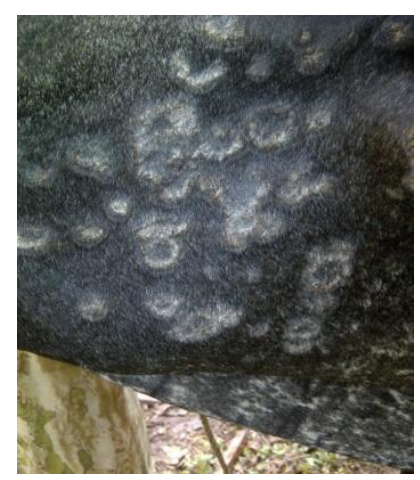

\section{Plate5:Gradually} decreasing lesion of ring-worm in infected animal.

There were no haemoparasites in blood samples, $\mathrm{PCV}, \mathrm{HB}$ and other haematological values were within normal range. 


\section{DISCUSSION}

Dermatophilosis ranks as one of the four main bacteriological diseases of cattle in Nigeria with equivalent importance to CBPP and Brucellosis ${ }^{[7,8]}$. It represents one of the major skin diseases found in ruminants in Umuahia and occurs much more commonly than any other condition. It is a potential zoonotic disease as well as ring worm. Several factors are involved in its pathogenesis; among them are mechanical injury to the skin, rainfall, tick infestation, concurrent diseases and stress that compromise the host immune system. It is generally accepted that in the rainy season, owing to devitalizing effect on the skin barriers, the high relative humidity has a significant influence on the maturation and motility of the infective zoospores, and it has been claimed to be a major predisposing factor in the spread and epidemiology of dermatophilosis ${ }^{(9)}$. In this case it is the major herd health problem. Clinical signs are seldom confused with other conditions. The interesting finding here remains the presence of mites which rarely comes to the mind of most clinician especially when obvious clinical dermatophilosis is observed. Presence of ticks is commonly encountered and usually gives instant explanation to observed condition and most often when demodectic mange is not suspected, other mites are usually not incriminated. Diagnosis is made based on clinical appearance of the lesion on the affected animal and confirmed by demonstration the causal organism from skin scrapings, crust or scabs ${ }^{(10)}$. The outcome of treatment is influenced by the severity and extent of lesions. Parenterally administered antibiotics such as long acting oxytetracyclines are said to be effective ${ }^{(11,12)}$ but often is of little significance in most field cases in this part of the world. The combination therapy with ivermectin and antinflammatory agent gives a more positive response (plate 4). Crusts and scabs fall off within 3-7 days as response to treatment leaving dry surfaces on the skin. Full recovery is observed when new hairs grow and cover skin the surfaces. Control and prevention measures are based on minimizing the effect of predisposing factors and early treatment of clinical cases ${ }^{[12]}$. The disease often results in economic problems by creating severe skin matting resulting in hide depreciation, overall decrease in animal' market price, decrease productivity and in severe cases mortality in susceptible weak animals ${ }^{[13]}$. Most cattle owners cull of affected animals when lesions are extensive.

Dermatomycosis more commonly known as ring worm caused by trichophyton and mycosporum species was the second condition of interest; it affects skin integuments of animals is highly zoonotic; About $80 \%$ of human ring waorm cases are said to be from animals. Infected animals may act as reservoirs of human infections. Economic losses incurred as cost of treatment could be important if affected animals are high priced such as exotic breeding animals or research animals ${ }^{[5,6]}$. It is not a major disease of ruminants in this herd it was found on two animals and had not spread to other. It was severe due to concurrent dermatophilosis. As seen in plate 5 the lesion had substantially decreased with management taking care of dermatophilosis. The combination therapy using oxytetracycline and ivermectin which was $100 \%$ successful in this case is an evidence that eliminating concurrent and discrete mite infestation which causes cutaneous maceration will result in efficient treatment of the disease since treatment with oxytetracyclines rarely achieves $100 \%$ clearance ${ }^{[14,15,16]}$ and in most cases is ineffective at normal doses under field conditions.

This case highlights two important zoonotic conditions that require proper attention with regard to improving cattle production and prevention of such condition from affecting human populations. Prevention of such diseases in animal population will be done by efficient control of ectoparasites such as ticks, mites, fleas; rapid diagnosis and treatment of affected animals; proper disinfection of animal housing, beddings, equipments and animal environment. Training cattle owner on rapid identification and presentation of affected animal for veterinary professional attention will enhance control capabilities. 


\section{REFERENCES}

1. Radostits O. M., Gay C. C., Hinchichiff K.W., Constable P. D. (2007). Veterinary Medicine, a Text Book of the Diseases of Cattle, Sheep, Pigs, Goats and Horses. 10thed. Philadelphia: Saunders. Pp. 10481050.

2. Andrew AH, Blawey RW, Boyd H, Eddy RG (2003): Bovine Medicine, Disease and Husbandry of Cattle. 2nded. United Kingdom: Black Well Science. Pp. 886-887.

3. Yeruham, I., D. Elad and S. Perl, 2000. Economic aspects of outbreaks of dermatophilosis in firstcalving cows in nine herds of dairy cattle in Israel. Vet Rec., 146(24): 695-8.

4. M. C. Radostis, D.C. Blood, C. C. Gay (1986): A textbook of diseases of cattle sheep Pigs Goats and horses. Eight edition pp: 857-861; 1164-1167.

5. Kahn C.M. Scott Line (2010): The Merck Veterinary Manual, tenth Edition, pp: 782784

6. Scott D. B. (1994): Mycoses. In Coetzer J A W,Thomson G R, Tustin R.C (eds) Infectious diseases of livestock with special reference to South Africa, Vol 2. Oxford University Press, Cape Town: 1521-1533

7. Oduye, O.O. and D.H. Lloyd, 1971. Incidence of bovine cutaneous streptothricosis in Nigeria. Br Vet. J., 127: 505-510.

8. Sekoni, V.O., 1993. Effects of severe chronic scrotal Dermatophilus congolensis (kirchi) infection on semen characteristics in Zebu/Friesian crossbred bulls and effect of long-acting terramycin chemotherapy. Theriogenology, 40(1): 211-23.

9. Yeruham I, Elad D, Perl S (2003): Dermatophilosis in goats in the Judean foothills. Revue Med. Vet, 12: 785-786.

10. Kahn C.M. (2005): The Merck Veterinary Manual. 9thed. USA: Merck and Co.Inc. Pp. 690-691.
11. Awad W. S., Nadra E, Abdou M.I., El-sayed A. A. (2008): Diagnosis and Treatment of Bovine, Ovine and Equine Dermatophilosis. Journal of Applied Sciences Research, 4: 366-367.

12. Awad WS, Nadra E, Abdou MI, El-sayed AA (2008). Diagnosis and Treatment of Bovine, Ovine and Equine Dermatophilosis. Journal of Applied Sciences Research, 4: 366-367.

13. Haward J.L. (1996). Current Veterinary Therapy, Food Animal Practice. 2nded. Philadelphia: Black Well Saunders. Pp. 610611.

14. Quinn PJ, Markey BK (2003): Concise Review of Veterinary Microbiology. 1sted. Britain: Black Well Publishing. Pp.69-70

15. Dalis SJ, Kazzem HM, Makinde AA, Fatihu MY (2010). Bacteria associated with Bovine Dermatophilosis in Zaria, Nigeria. Africa Journal of Microbiology, 4: 1475-1476.

16. Stewart G.H. (1997): Dermatophilosis, a Skin Disease of Animals and Man. The Veterinary Record, 99: 534-536.

17. OIE (2008): Dermatophilosis Terrestrial manual, Pp. 725-727.

18. Harman, M., S. Sekin and S. Akdeniz, (2001).Human dermatophilosis mimicking ringworm. BrJ Dermatol., 145(1): 170-1.32.

19. Wabacha, J.K.; Gitau, G.K.; Bebora, L. C.; Bwanga, C. O.; Wamuri, Z. M.; Mbithi, P. M. F. (1998): Occurrence of dermatomycosis (ringworm) due to Trichophyton verrucosum in dairy calves and its spread to animal attendants. Journal of the South African Veterinary Association 69(4):172-173 